\title{
Hearing impairment in WBN/Kob rats with spontaneous diabetes mellitus
}

\author{
T. Ishikawa ${ }^{1}$, Y. Naito ${ }^{1}$, K. Taniguchi ${ }^{2}$ \\ ${ }^{1}$ Department of Veterinary Internal Medicine, Faculty of Agriculture, Iwate University, Iwate, Japan \\ ${ }^{2}$ Department of Veterinary Anatomy, Faculty of Agriculture, Iwate University, Iwate, Japan
}

Summary The inner ear of spontaneously diabetic WBN/Kob rats was functionally and morphologically examined in order to elucidate the relationship between diabetes mellitus and hearing impairment. At 3 months of age, WBN/Kob rats were non-diabetic, and their hearing function was normal. At 67 months of age, they showed decreased glucose tolerance and an increasing tendency toward urinary excretion of glucose without high plasma concentration of glucose, and were therefore judged to be pre-diabetic. They also displayed a significant elevation of hearing threshold in the auditory brainstem response, but showed little morphological and histochemical changes in the inner ear. At 12-13 months of age, they were spontaneously diabetic and showed a more apparent elevation of hearing threshold in auditory brainstem response than that in pre-diabetic ani- mals. In addition, they displayed a marked decrease in the number of spiral ganglion cells and oedematous changes in the stria vascularis. The stria vascularis also showed a decrease in the intensity of staining with some lectins, i.e., wheat germ agglutinin, succinylated wheat germ agglutinin, Soranum tuberosum lectin, and concanavalin A. In conclusion, hearing impairment is induced by diabetes in the WBN/ Kob rats first as an elevation of hearing threshold along with glucose intolerance; secondly, as a decrease in the number of spiral ganglion cells; and thirdly, as oedematous change of the stria vascularis with decreased intensity of lectin staining. [Diabetologia (1995) 38: 649-655]

Key words Diabetes mellitus, hearing impairment, $\mathrm{WBN} / \mathrm{Kob}$ rats, inner ear, lectins.
Although diabetes mellitus has been investigated both clinically [1-8] and pre-clinically [9-13] in association with hearing loss, the developmental mechanism of hearing impairment in diabetes has not been fully elucidated mainly because of difficulties in func-

Received: 20 September 1994 and in revised form 14 December 1994

Corresponding author: Dr.T. Ishikawa, Toxicology Laboratory, Mochida Pharmaceutical Co., Ltd., 342 Gensuke, Fujieda-city, Shizuoka 426, Japan

Abbreviations: ABR, Auditory brainstem response; WGA, wheat germ agglutinin; sWGA, succinylated wheat germagglutinin; STL, Soranum tuberosum lectin; BSL-II, Bandeiraea simplicifolia lectin-II; VVA, Vicia villosa agglutinin; ConA, concanavalin A; PHA-E, Phaseolus vulgaris erythroagglutinin; PHA-L, Phaseolus vulgaris leucoagglutinin; ABC, Vectastain avidin-biotin complex. tional and morphological examinations simultaneously on human subjects. However, we studied WBN/Kob rats which are derived from Wistar rats [14] and develop diabetes spontaneously due to endocrine-exocrine pancreatic insufficiency [15-19]. They begin to excrete odorous urine abundantly at the age of about 9 months, and thereafter show hyperglycaemia and marked intolerance to glucose. Since they can survive for a long time after the onset of diabetes without insulin treatment, they are a pertinent animal model for analysis of various aspects of diabetes [20, 21]. In the present study, therefore, male WBN/Kob rats with spontaneous diabetes underwent functional, morphological, and histochemical examinations to determine the effects of diabetes on auditory function. 


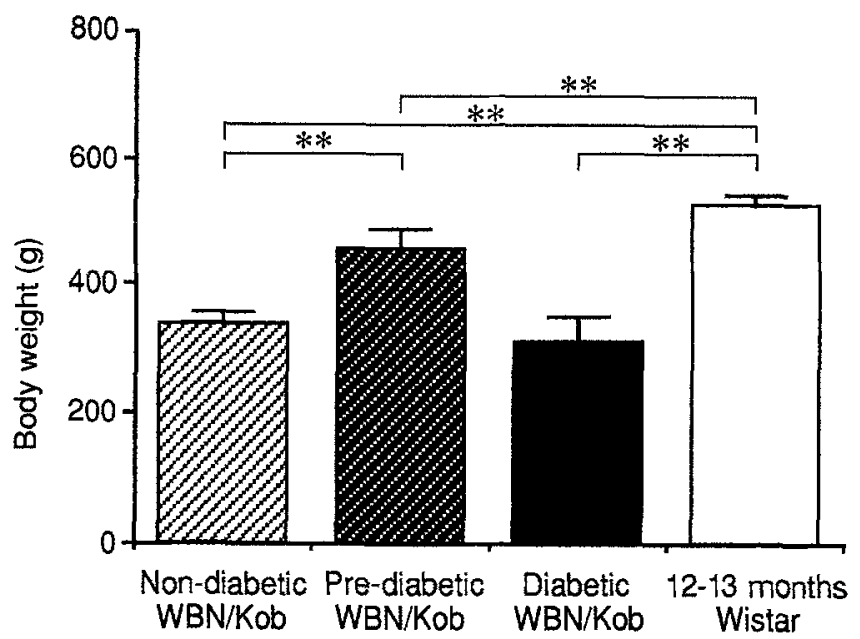

Fig. 1. Average body weight of male non-diabetic, pre-diabetic and diabetic WBN/Kob rats, and of male Wistar rats at 1213 months of age. Each column represents the mean $\pm \mathrm{SD}$ $(n=5)$. Significant difference from the non-diabetic WBN/ Kob rats or the control Wistar rats $* * p<0.01$

\section{Materials and methods}

Animals. Twenty WBN/Kob and ten Wistar male rats were obtained at 1 month of age from Shizuoka Laboratory Animal Center (Shizuoka, Japan) and kept for 2 to 12 months. The animals were individually housed in stainless steel cages $(310 \times 270 \times 175 \mathrm{~mm})$ and fed standard rat chow (MB-3, Funabashi Farm, Japan) and tap water ad libitum in an animal room with a ventilation capacity of 15 exchanges of room air per hour under controlled temperature $\left(23 \pm 2^{\circ} \mathrm{C}\right)$, controlled relative humidity $(55 \pm 10 \%)$, and a 12 -h light/dark cycle (lights on 07.00 to 19.00 hours).

Reagents. Nine biotinylated lectins, wheat germ agglutinin, succinylated wheat germ agglutinin, Soranum tuberosum lectin, Bandeiraea simplicifolia lectin-II, Vicia villosa agglutinin, jacalin, concanavalin A, Phaseolus vulgaris erythroagglutinin, and Phaseolus vulgaris leucoagglutinin and Vectastain avidinbiotin complex kits were obtained from Vector Laboratories, Inc. (Burlingame, Calif., USA). These lectins bound specifically with the cochlea of the normal Wistar rats in our preliminary examinations (data not shown).

Clinical examinations. Clinical signs, body weight, urinary volume, and plasma and urinary glucose levels (hexokinase method, autoanalyzer Cobas Fara; Roche, Basel, Switzerland) were measured in each rat at intervals of 1 or 3 months throughout the experimental period. One week before killing, the animals were treated orally with glucose at a dose of $2 \mathrm{~g} / \mathrm{kg}$ to determine plasma glucose concentration at 30, 60, and $120 \mathrm{~min}$ after administration for ascertaining glucose tolerance.

Auditory brainstem response $(A B R)$. ABR was recorded in a quiet room in order to estimate the hearing threshold of WBN/Kob rats aged 3, 6-7, and 12-13 months and of Wistar rats aged $12-13$ months. Under pentobarbital sodium ( $40 \mathrm{mg}$ / $\mathrm{kg}$ body weight, i. p.) anaesthesia, which has no effect on $\mathrm{ABR}$ patterns $[22,23]$, the animals were kept warm at a rectal temperature of about $38^{\circ} \mathrm{C}[24,25]$, and elicited their $A B R$ to record its pattern with a signal processor (7S-12, NEC San-ei, Tokyo, Japan). Click stimuli of alternating polarity were generated by the signal processor under the conditions of $10 \mathrm{~Hz}$ and
T. Ishikawa et al: Hearing impairment in diabetic WBN/Kob rats

0.1-ms duration. Clicks were monaurally delivered through hollow earbars inserted in the right and left external auditory meatuses of the rats. Small enamel-covered stainless wire electrodes $(120-\mu \mathrm{m}$ in diameter) were set subcutaneously at three sites: an active electrode $(+)$ at the vertex, a reference electrode $(-)$ at the base of the stimulated ear, and a ground electrode at the neck.

Histopathological examinations. A few days after the recording of $\mathrm{ABR}$, the animals were transcardially perfused with physiological saline followed by Bouin's fixative under pentobarbital sodium anaesthesia $(50 \mathrm{mg} / \mathrm{kg}$ body weight, i. p.). After decapitation, the temporal bones including the inner ear were dissected out and immersed in the same fixative overnight. The specimens were decalcified in Plank-Rychlo's solution [26] and embedded in paraffin by routine procedures. Paraffin sections were cut serially at $4 \mu \mathrm{m}$ thick, deparaffinized with xylene, and stained with haematoxylin and eosin (H.E.) or processed for lectin staining. H.E.-stained sections were examined morphometrically with an image analyser (Luzex 3; Nireco, Tokyo, Japan) to measure the gross area of spiral ganglion cells.

Lectin-histochemical examinations. In the lectin staining, serial sections were incubated separately with nine biotinylated lectins for about $16 \mathrm{~h}$ at $4^{\circ} \mathrm{C}$. After incubation, lectin-binding sites were visualized by the Vectastain $\mathrm{ABC}$ kit. Control lectin stainings were performed by preabsorption of each lectin with a sufficient amount of its corresponding inhibitory sugar [27] or by the use of phosphate-buffered saline to replace the biotinylated lectins or $\mathrm{ABC}$ for the confirmation of the specificity of lectin bindings.

\section{Statistical analysis}

The data were statistically analysed by Student's $t$-test. A difference from the respective control was regarded as statistically significant at the $p<0.05$ level.

\section{Results}

Body weight and clinical findings. The average body weight of the WBN/Kob rats was significantly higher just before the onset of diabetes, i.e., at the age of 6 7 months, than at the age of 3 months, but markedly decreased at the age of 12-13 months to slightly lower than that at the age of 3 months (Fig. 1). We defined the WBN/Kob rats aged $3,6-7$ and 12 13 months as non-diabetic, pre-diabetic and diabetic, respectively, according to the clinical findings described in the following, and used the Wistar rats at the age of $12-13$ months as the control.

The plasma concentration of fasting glucose was significantly higher in the diabetic WBN/Kob rats than that in the non-diabetic $(5.8 \pm 0.6 \mathrm{mmol} / \mathrm{l})$ or pre-diabetic $(6.4 \pm 0.4 \mathrm{mmol} / \mathrm{l}) \mathrm{WBN} / \mathrm{Kob}$ rats and attained a value of over $30 \mathrm{mmol} / \mathrm{l}$. In the glucose tolerance test, the plasma levels of glucose and the rate of its disappearance from the plasma in the non-diabetic WBN/Kob rats were similar to those in the control Wistar rats. The plasma glucose levels were higher in all the pre-diabetic WBN/Kob rats than in the non- 


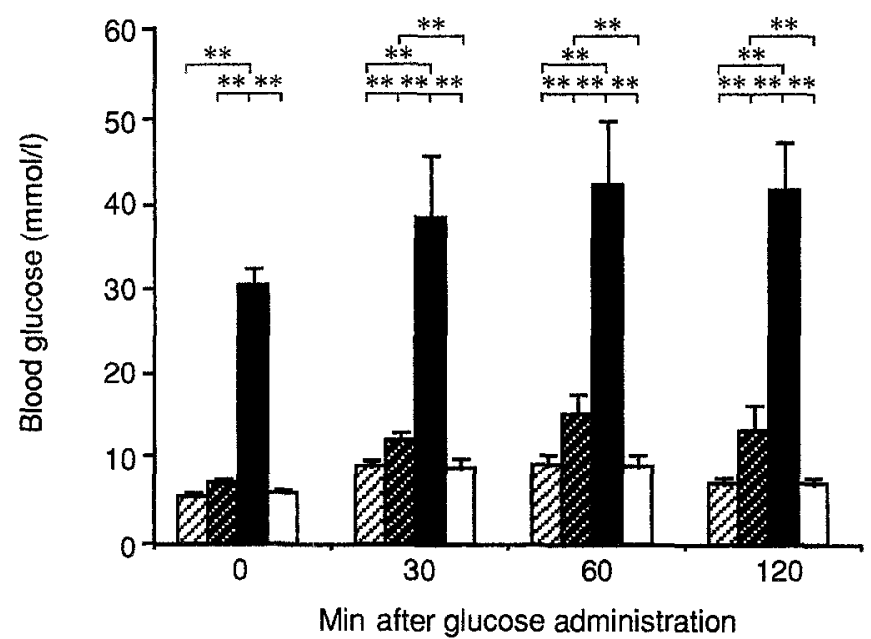

Fig. 2. Oral glucose tolerance test in male non-diabetic (䍿), pre-diabetic ( and diabetic ( W W W male Wistar rats $(\square)$ at 12-13 months of age. Each column represents the mean $\pm \mathrm{SD}(n=5)$. Statistical significance in the non-diabetic, pre-diabetic and diabetic WBN/Kob rats, and the control Wistar rats $* * p<0.01$
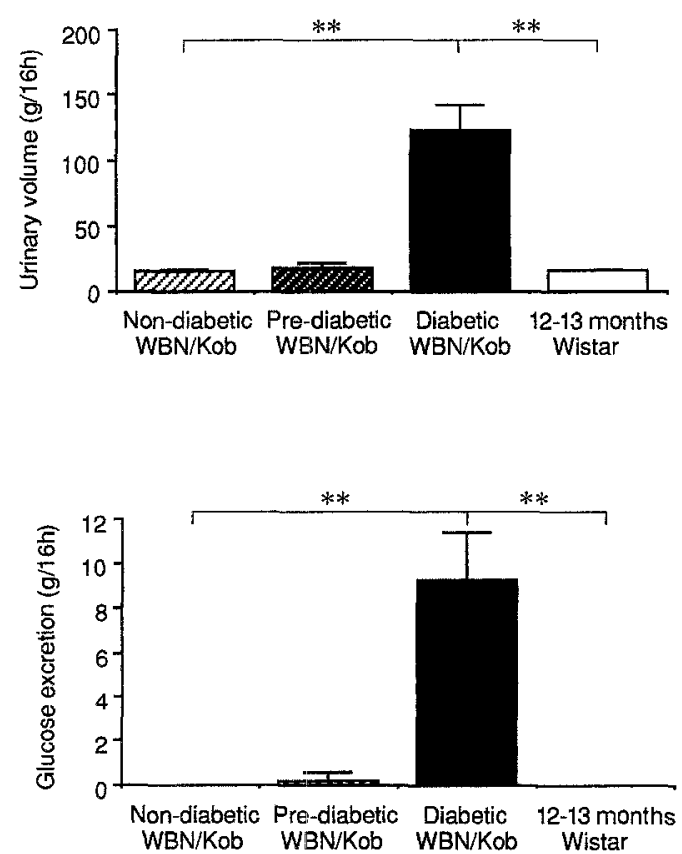

Fig.3. Average urinary volume and glucose excretion in male non-diabetic, pre-diabetic and diabetic WBN/Kob rats, and in male Wistar rats at 12-13 months of age. Each column represents the mean $\pm \mathrm{SD}(n=5)$. Significant difference from the non-diabetic WBN/Kob rats or the control Wistar rats $* * p<0.01$

diabeticWBN/Kob rats at 30,60, and $120 \mathrm{~min}$ after oral administration of glucose $(2 \mathrm{~g} / \mathrm{kg})$, although the rate of its disappearance from the plasma was $2.2 \mathrm{mmol} / 30 \mathrm{~min}$ and comparable to that of the nondiabetic WBN/Kob rats $(2.3 \mathrm{mmol} / 30 \mathrm{~min})$ or the control Wistar rats $(1.9 \mathrm{mmol} / 30 \mathrm{~min})$. The plasma glucose levels were five to six times higher in the diabetic WBN/Kob rats than in the non-diabetic WBN/

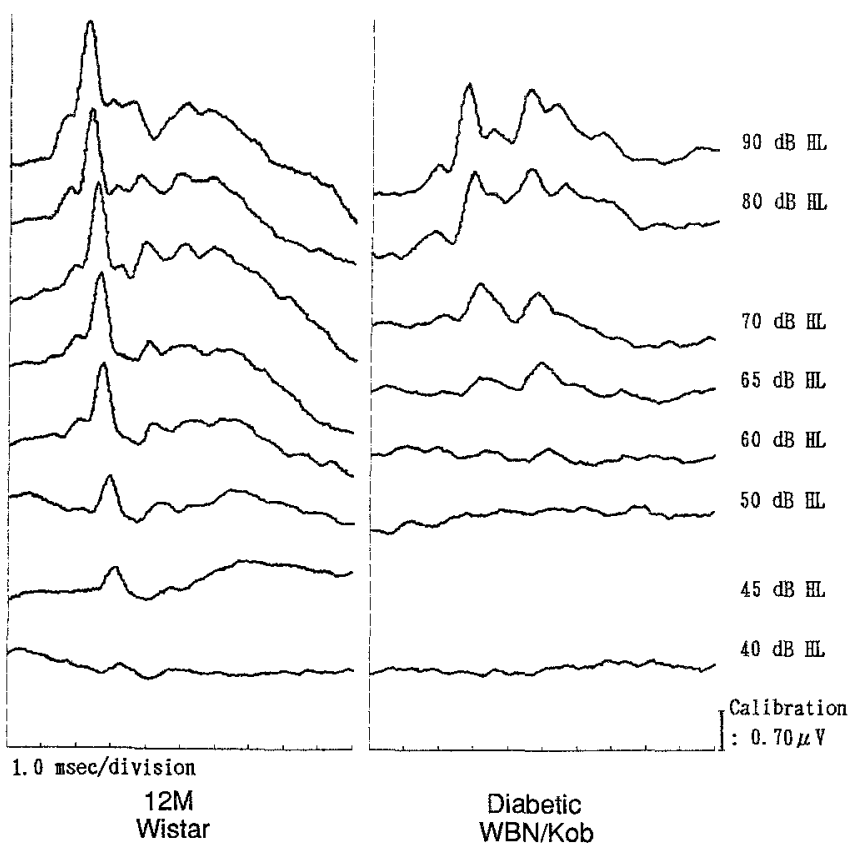

Fig. 4. Typical ABR patterns (right ear) from a control Wistar rat at 12 months of age (hearing threshold: $45 \mathrm{~dB}$ HL) and from a diabetic WBN/Kob rat (hearing threshold: $65 \mathrm{~dB} \mathrm{HL}$ ). HL, Hearing level

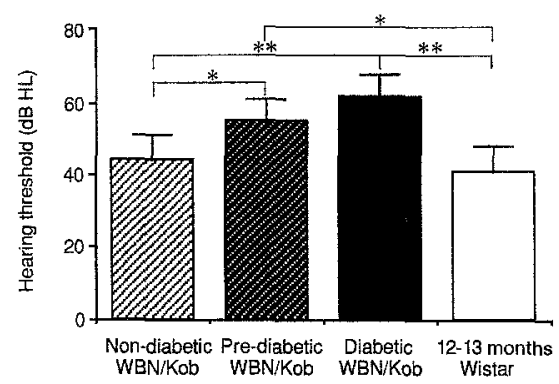

Fig.5. Average hearing thresholds (right ear) in male non-diabetic, pre-diabetic and diabetic WBN/Kob rats, and in male Wistar rats at $12-13$ months of age. Each column represents the mean $\pm \mathrm{SD}(n=5)$. Significant differences from the nondiabetic WBN/Kob rats or the control Wistar rats $* p<0.05$; $* * p<0.01$

Kob rats. In the diabetic WBN/Kob rats, the plasma glucose levels showed no difference between 30 and 120 min after glucose administration because of the retardation in its disappearance from the plasma. These results are summarized in Figure 2.

The urinary volume and glucose excretion showed significant and marked increases in the diabetic $\mathrm{WBN} / \mathrm{Kob}$ rats in comparison with those in the nondiabetic WBN/Kob rats, while the glucose excretion was only low in the pre-diabetic WBN/Kob rats (Fig. 3).

Hearing threshold in $A B R$. The typical patterns of the click stimuli in the diabetic WBN/Kob rat and the control Wistar rat are recorded as shown in Figure 4. Five to six peaks were observed in the ABR patterns 
Table 1. Histopathological findings on the cochleae in WBN/Kob and Wistar rats

\begin{tabular}{|c|c|c|c|c|}
\hline \multirow[t]{2}{*}{ Strain } & \multirow{2}{*}{$\begin{array}{l}\text { Age } \\
\text { (months) }\end{array}$} & \multirow{2}{*}{$\begin{array}{l}\text { No. of } \\
\text { animals }\end{array}$} & Spiral ganglion & Stria vascularis \\
\hline & & & $\begin{array}{l}\text { Decrease in number } \\
\text { of ganglion cells }\end{array}$ & $\begin{array}{l}\text { Oedema of inter- } \\
\text { mediate cells }\end{array}$ \\
\hline \multirow[t]{3}{*}{ WBN/Kob } & $\begin{array}{l}3 \\
\text { (non-diabetic) }\end{array}$ & 5 & $\overline{(72.0 \pm 4.8)^{\mathrm{a}}}$ & - \\
\hline & $\begin{array}{l}6 \sim 7 \\
\text { (pre-diabetic) }\end{array}$ & 5 & 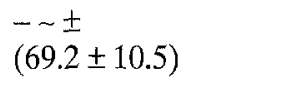 & - \\
\hline & $\begin{array}{l}12 \sim 13 \\
\text { (diabetic) }\end{array}$ & 5 & $\begin{array}{l} \pm \sim++ \\
(41.5 \pm 10.2)\end{array}$ & $\pm \sim+$ \\
\hline Wistar & $12 \sim 13$ & 5 & $\overline{-}(73.5 \pm 2.6)$ & - \\
\hline
\end{tabular}

${ }^{a}$ Ratio of area of ganglion cells to Rosenthal's canal. Values are $\%$ mean \pm SD.

Grade of changes: -, no lesion; \pm , slight; + , moderate; ++, severe
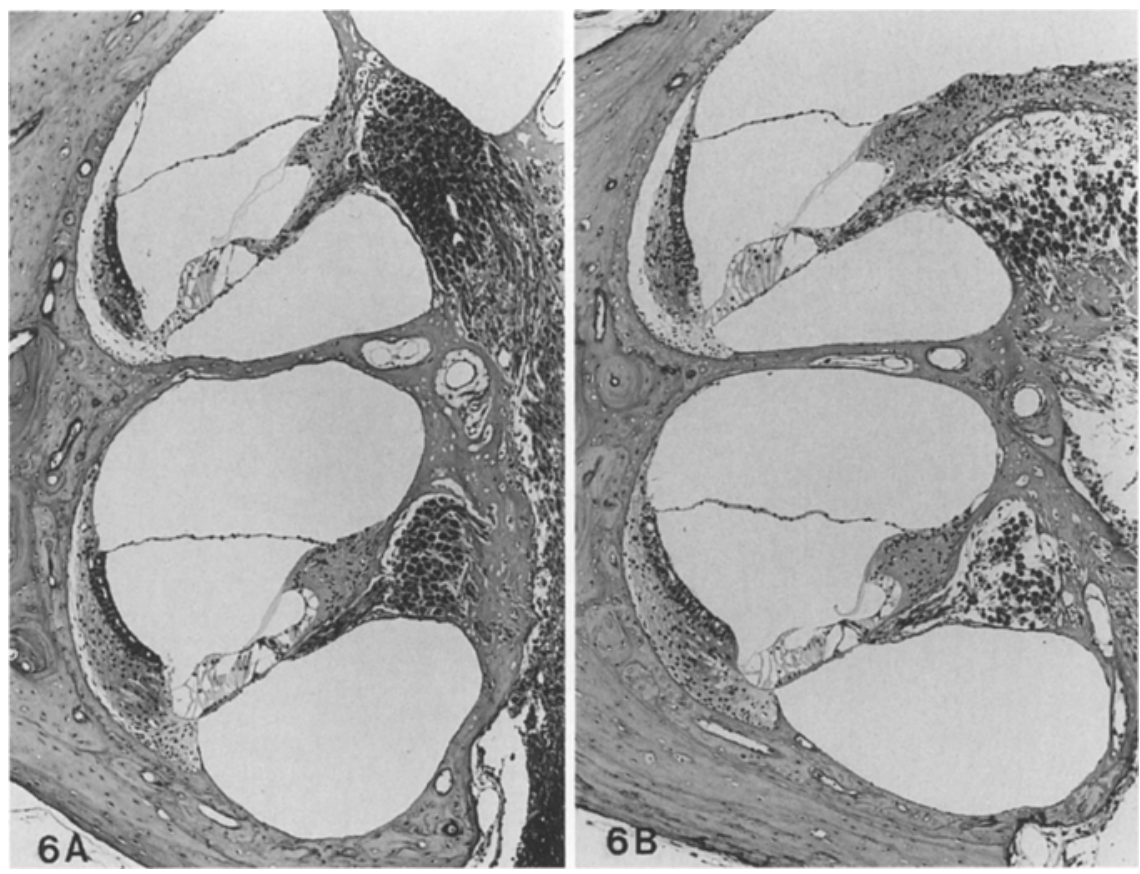

Fig. 6 (A, B). Inner ear of a control male Wistar rat at 12 months of age (A) and an age-matched diabetic male WBN/Kob rat (B). Loss of spiral ganglion cells and oede$\mathrm{ma}$ of the stria vascularis are evident in the diabetic male WBN/Kob rat. H.E., $\times 80$ of each animal at the sound pressure levels over the auditory threshold. As the amplitude of the second peak was the highest among them, the hearing threshold was defined as the level at which the second peak could be distinguished.

The average hearing thresholds of the right ear of the non-diabetic, pre-diabetic and diabetic WBN/ Kob rats were $44 \pm 7,55 \pm 6$, and $62 \pm 6 \mathrm{~dB} \mathrm{HL}$ (hearing level), respectively, and were similar to those of the left ear. The threshold was significantly higher in pre-diabetic and diabetic WBN/Kob rats than that in the non-diabetic WBN/Kob rats. The average hearing threshold was comparable in the nondiabetic WBN/Kob rats to that in the control Wistar rats. These results are shown in Figure 5.

Histopathological findings. The histopathological findings on the cochleae in WBN/Kob and Wistar rats are summarized in Table 1 . H.E.-stained sections of the inner ear of a control male Wistar rat and a diabetic male WBN/Kob rat are illustrated in Figures 6 and 7. Histopathological changes were focused on the spiral ganglion and the stria vascularis in the cochleae of the diabetic WBN/Kob rats. They involved a decrease in the number of the spiral ganglion cells and oedematous change in the stria vascularis. The latter change was predominant in the intermediate cells. One out of five pre-diabetic WBN/ Kob rats showed a slight decrease in the number of the spiral ganglion cells. In contrast, the inner and outer hair cells showed no histopathological changes in any WBN/Kob rat.

Lectin-histochemical findings. The lectin-binding patterns of the cochleae in WBN/Kob and Wistar rats are summarized in Tables 2 and 3 . The intermediate cells 

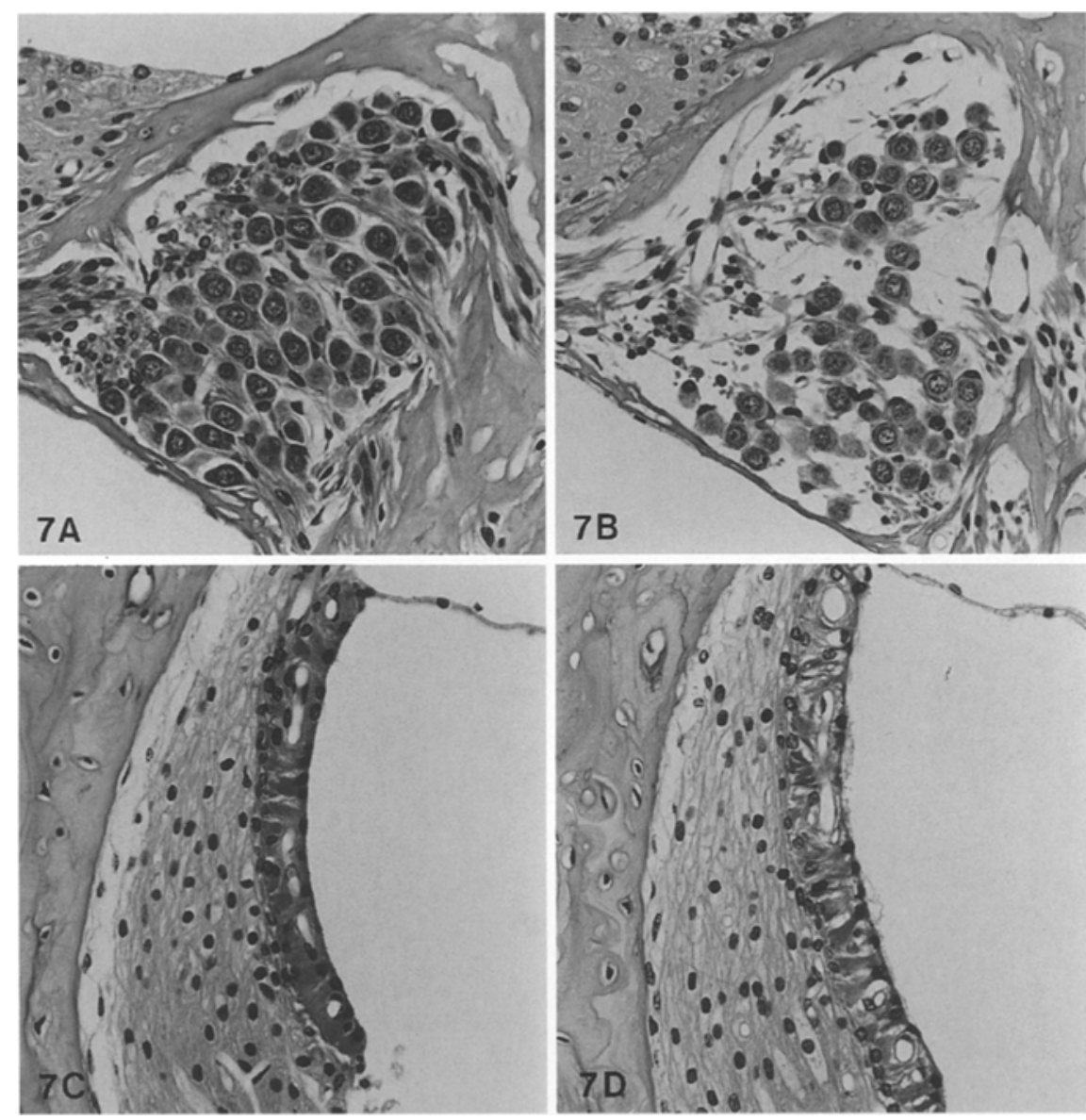

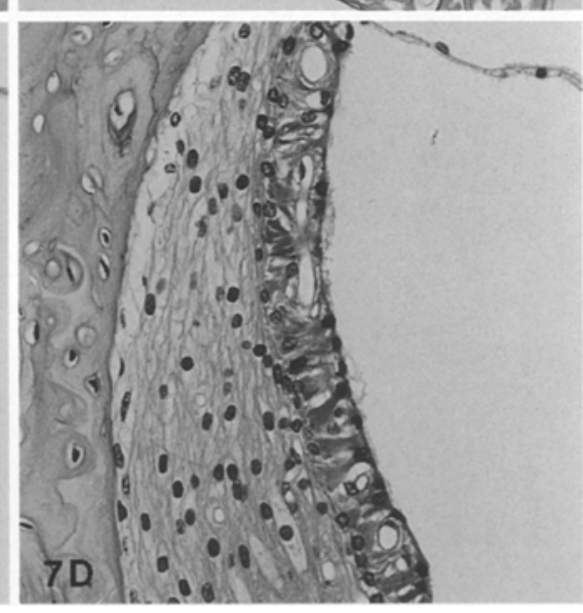

Fig. 7 (A-D). High magnifications of the spiral ganglion $(\mathbf{A}, \mathbf{B})$ and stria vascularis $(\mathbf{C}, \mathbf{D})$ of the same animals as shown in Figure 6 . There are no abnormalities in the control male Wistar rat $(\mathbf{A}, \mathbf{C})$. The decrease in the number of spiral ganglion cells (B) and oedematous change in the intermediate cells of the stria vascularis (D) are evident in the diabetic male WBN/ Kob rat. H.E., $\times 330$

Table 2. Lectin binding patterns of the cochleae (stria vascularis) in WBN/Kob and Wistar rats

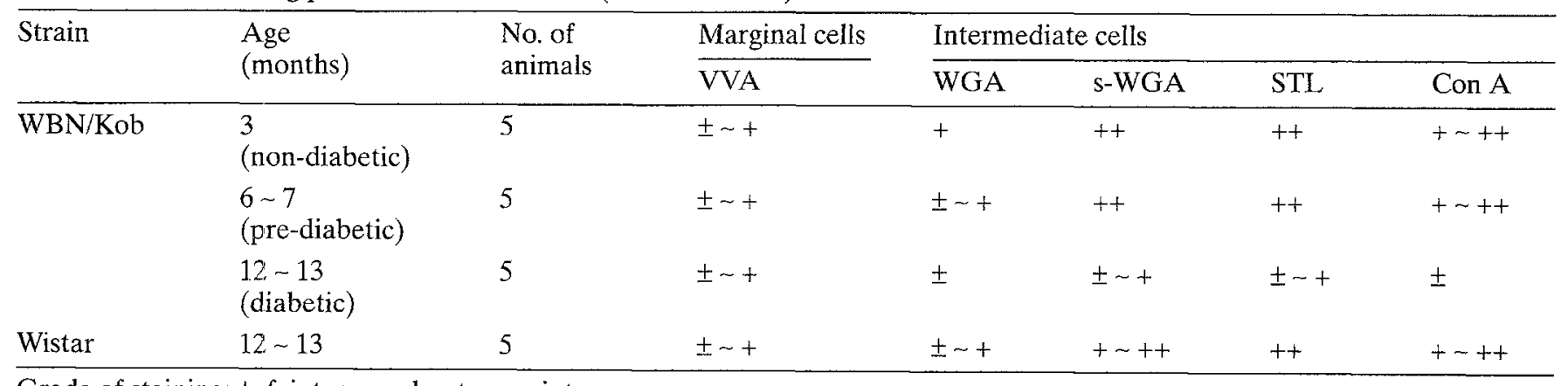

Grade of staining: \pm , faint; + , moderate; ++ , intense

of the stria vascularis in the diabetic WBN/Kob rats were more weakly stained with WGA, s-WGA, STL, and Con A lectins than those in the non-diabetic or pre-diabetic WBN/Kob rats. Lectin stainings of the stria vascularis with STL are compared between a control male Wistar rat and a diabetic male WBN/ Kob rat in Figure 8. On the other hand, the superficial or marginal cells were specifically stained with VVA throughout all the non-diabetic, pre-diabetic and diabetic WBN/Kob rats and control Wistar rats. There were no differences in the staining intensity of Con A, jacalin, PHA-E, and PHA-L in the spiral ganglion cells, or that of BSL-II in the outer hair cells between the pre-diabetic and diabetic WBN/Kob rats.

\section{Discussion}

With respect to the changes in body weight, WBN/Kob rats showed an ordinary and progressive increase in body weight until 6-7 months of age (pre-diabetic stage), but a decrease at the age of 12-13 months (diabetic stage). They did not develop diabetic obesity.

In the oral glucose tolerance test, the fasting plasma glucose levels, glucose tolerance, and urinary glu- 
Table 3. Lectin binding patterns of the cochleae (spiral ganglion) in WBN/Kob and Wistar rats

\begin{tabular}{lllllll}
\hline Strain & $\begin{array}{l}\text { Age } \\
\text { (months) }\end{array}$ & $\begin{array}{l}\text { No. of } \\
\text { animals }\end{array}$ & \multicolumn{4}{l}{ Ganglion cells } \\
\cline { 5 - 6 } & $\begin{array}{l}3 \\
\text { (non-diabetic) }\end{array}$ & 5 & Con A & Jacalin & PHA-E & PHA-L \\
\hline WBN/Kob & 5 & $+\sim++$ & $\pm \sim+$ & $\pm \sim+$ & \pm \\
& $\begin{array}{l}6 \sim 7 \\
\text { (pre-diabetic) }\end{array}$ & 5 & $+\sim++$ & $\pm \sim+$ & $\pm \sim+$ & \pm \\
& $\begin{array}{l}12 \sim 13 \\
\text { (diabetic) }\end{array}$ & 5 & $+\sim++$ & $\pm \sim+$ & \pm & \pm \\
Wistar & $12 \sim 13$ & 5 & $+\sim++$ & $\pm \sim+$ & $\pm \sim+$ & $\pm \sim+$ \\
\hline
\end{tabular}

Grade of staining: \pm , faint; + , moderate; ++ , intense

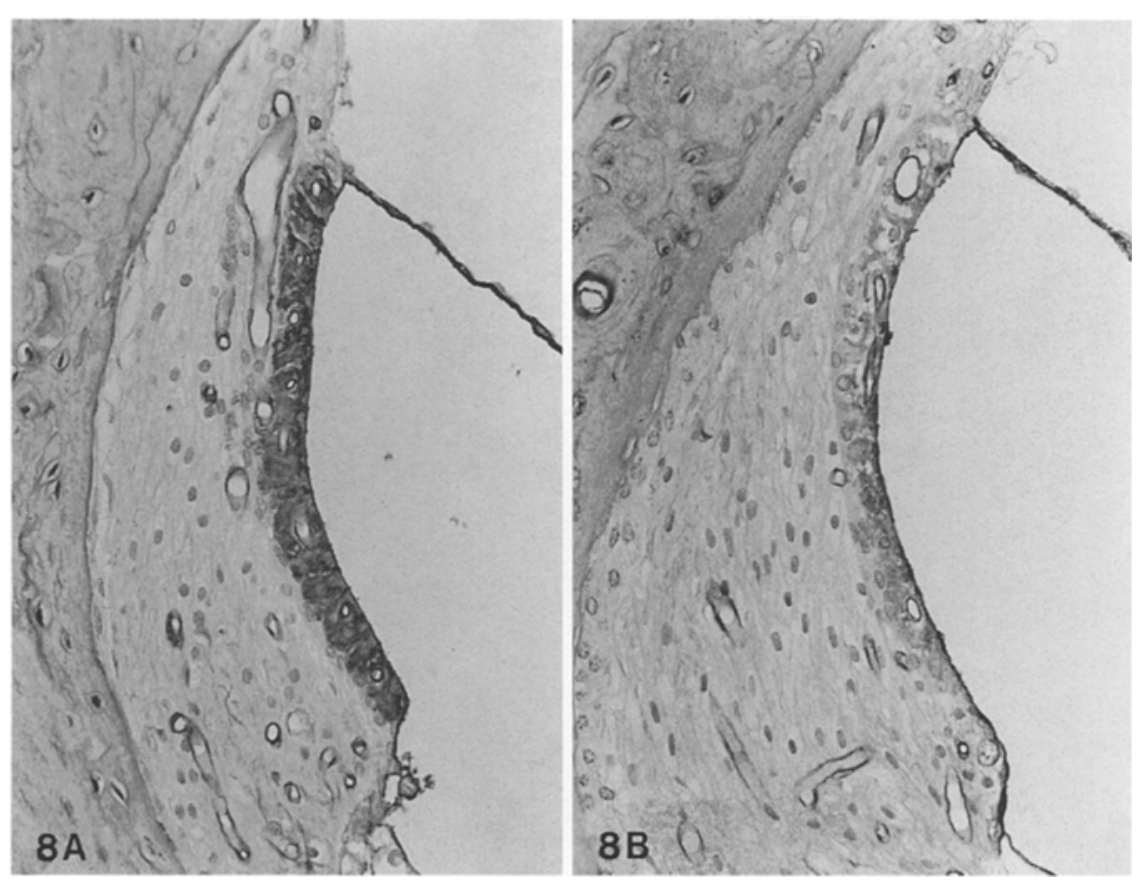

Fig. 8 (A, B). Stria vascularis of a control male Wistar (A) and diabetic male WBN/ Kob rat (B). In the control male Wistar rat, marginal and intermediate cells in the stria vascularis are stained intensely with STL, while in the diabetic WBN/Kob rat, intermediate cells are only faintly stained with STL. $\times 330$ cose were normal in the non-diabetic WBN/Kob rats aged 3 months when compared with those in the control Wistar rats. WBN/Kob rats aged 6-7 months were almost normal in their fasting plasma glucose levels, but were slightly intolerant of glucose and negative or falsely positive for urinary glucose, and regarded as pre-diabetic. On the other hand, WBN/Kob rats aged 12-13 months were significantly high in their fasting plasma glucose levels, apparently intolerant to glucose, positive for urinary glucose and polyuria, and were concluded to be diabetic.

The auditory function was examined by the ABR. The hearing thresholds of non-diabetic WBN/Kob rats were comparable to those of the control Wistar rats. In contrast, those of pre-diabetic and diabetic WBN/Kob rats were significantly high depending on the severity of the diabetes.

Although histopathological changes such as thickening of the vessel wall in the stria vascularis and spiral ligament $[1,4]$, hair cell loss in the organ of Corti, and spiral ganglion atrophy [3] have been reported in the inner ear of human subjects, it is not always clear whether these changes are primarily due to diabetes. There are too many complicating factors to resolve this problem $[6,7]$.

In the present study, the decrease in the number of spiral ganglion cells and the oedematous change in the intermediate cells of the stria vascularis were observed in the inner ear of the diabetic WBN/Kob rats. The latter was similar to the reversible and oedematous changes in the stria vascularis of guinea pigs treated with diuretics such as furosemide, which is potentially ototoxic [28-30]. In addition, one of five pre-diabetic WBN/Kob rats revealed a slight decrease in the number of spiral ganglion cells without changes in the stria vascularis. This animal showed the highest elevation of hearing threshold in the same age group. These findings may suggest that the hearing impairment is primarily caused by the decrease in the number of spiral ganglion cells and secondarily enhanced by the oedematous change in the stria vascularis. 
In lectin-histochemical examinations, the spiral ganglion cells in the diabetic rats were comparable to those in the non-diabetic and pre-diabetic rats in terms of staining intensity of Con A, jacalin, PHA-E, and PHA-L. These data suggest that the spiral ganglion cells are normal in function in spite of the decrease in their number. On the other hand, the intermediate cells of the stria vascularis were more weakly stained with WGA, s-WGA, STL, and Con A in the diabetic rats than those in the non-diabetic and prediabetic rats. The decrease in the intensity of staining may imply the dysfunction of the stria vascularis.

In summary, the present results indicate that the onset of hearing impairment is already evident at the pre-diabetic stage. The hearing impairment is further aggravated by the extensive decrease in the number of the spiral ganglion cells and the oedematous change in the intermediate cells of the stria vascularis. These findings suggest a significant relationship between diabetes and hearing impairment in this animal model.

\section{References}

1. Jorgensen MB (1961) The inner ear in diabetes mellitus. Arch Otolaryngol 74: 373-381

2. Jorgensen MB, Buch NH (1961) Studies on inner-ear function and cranial nerves in diabetics. Acta Oto-Laryngol 53: 350-364

3. Makishima K, Tanaka K (1971) Pathological changes of the inner ear and central auditory pathway in diabetics. Ann Otol Rhinol Laryngol 80: 218-228

4. Kovar M (1973) The inner ear in diabetes mellitus. Otol Rhinol Laryngol 35: 42-51

5. Friedman SA, Schulman RH, Weiss S (1975) Hearing and diabetic neuropathy. Arch Intern Med 135: 573-576

6. Gibben KP, Davis CG (1981) A hearing survey in diabetes mellitus. Clin Otolaryngol 6: 345-350

7. Harner SG (1981) Hearing in adult-onset diabetes mellitus. Otolaryngol Head Neck Surg 89: 322-327

8. Ferrer JP, Biurrun O, Lorente J et al. (1991) Auditory function in young patients with type I diabetes mellitus. Diabetes Res Clin Pract 11: 17-22

9. Costa OA (1967) Inner ear pathology in experimental diabetes. Laryngoscope 77: 68-75

10. Oliveira CA, Kruse C, Juhn SK (1977) Cochlea vascular changes in streptozotocin diabetes in chinchillas. Otol Rhinol Laryngol 84: 443-451

11. Buller N, Laurian N, Shvili I, Laurian L (1986) Delayed brainstem auditory evoked responses in experimental diabetes mellitus. J Laryngol Otol 100: 883-891

12. Triana RJ, Suits GW, Garrison S et al. (1991) Inner ear damage secondary to diabetes mellitus. Arch Otolaryngol Head Neck Surg 117: 635-640

13. Rubini R, Biasiolo F, Fogarolo F, Magnavita V, Martini A, Fiori MG (1992) Brainstem auditory evoked potentials in rats with streptozotocin-induced diabetes. Diabetes Res Clin Pract 16: 19-25

14. Kobori O, Gedigk O, Totovic V (1977) Adenomatous changes and adenocarcinoma of glandular stomach in Wistar rats induced by $\mathrm{N}$-methyl- $\mathrm{N}^{\prime}$-nitro- $\mathrm{N}$-nitrosoguanide. An electron microscopic and histochemical study. Virchows Archiv A 373: 37-54

15. Nakama K, Shichinohe K, Kobayashi K et al. (1985) Spontaneous diabetes-like syndrome in WBN/Kob rats. Acta Diabetol Lat 22: 335-342

16. Tsuchitani M, Saegusa T, Narama I, Nishikawa T, Gonda T (1985) A new diabetic strain of rat (WBM/Kob). Lab Anim 19: $200-207$

17. Mori Y, Yokoyama J, Nishimura M, Ikeda Y (1988) A new diabetic strain of rat with exocrine pancreatic insufficiency. In: Shafrir E, Renold AE (eds) Frontiers in Diabetes Research, Lessons from Animal Diabetes II. John Libbey, London, pp 324-326

18. Mori Y, Yokoyama J, Nishimura M, Kurata H, Miura J, Ikeda Y (1990) Diabetic strain (WBN/Kob) of rat characterized by endocrine-exocrine pancreatic impairment due to distinct fibrosis. Pancreas 5: 452-459

19. Ohashi K, Kim J, Hara H, Aso R, Akimoto T, Nakama K (1990) WBN/Kob rats. A new spontaneously occurring model of chronic pancreatitis. Int J Pancreatol 6: 231-247

20. Mori Y, Yokoyama J, Nishimura M, Oka H, Mochino S, Ikeda $Y$ (1992) Development of diabetic complications in a new diabetic strain of rat (WBN/Kob). Pancreas 7: 569-577

21. Yagihashi S, Wada R, Kamijo M, Nagai K (1993) Peripheral neuropathy in the WBN/Kob rat with chronic pancreatitis and spontaneous diabetes. Lab Invest 68: 296-307

22. Bobbin RP, May JG, Lemoine RL (1979) Effects of pentobarbital and ketamine on brain stem auditory potentials. Arch Otolaryngol 105: 467-470

23. Shapiro SM, Moller AR, Shiu GK (1984) Brain-stem auditory evoked potentials in rats with high-dose pentobarbital. Electroenceph Clin Neurophysiol 58: 266-276

24. Gold MC, Sohmer H, Horowitz M, Shahar A (1985) Effects of body temperature evolution on auditory nervebrain-stem evoked responses and EEGs in rats. Electroenceph Clin Neurophysiol 60: 146-153

25. Burkard R, Feldman M, Voigt HF (1990) Brainstem auditory-evoked response in the rat. Normative studies, with observations concerning the effects of ossicular disruption. Audiology 29: 146-162

26. Plank J, Rychlo A (1952) Eine Schnellentkalkungsmethode. Zentralbl path Anat 89: 252-254

27. Taniguchi K, Nii Y, Ogawa K (1993) Subdivisions of the accessory olfactory bulb, as demonstrated by lectin-histochemistry in the golden hamster. Neurosci Lett 158: 185188

28. Quick CA, Hoppe W (1975) Permanent deafness associated with furosemide administration. Ann Otol Rhinol Laryngol 84: 94-101

29. Forge A (1976) Observations on the stria vascularis of the guinea pig and the changes resulting from the administration of the diuretic furosemide. Clin Otolaryngol 1: 211219

30. Forge A, Brown AM (1982) Ultrastructural and electrophysiological studies of acute ototoxic effects of furosemide. Br J Audiol 16: 109-116 